\title{
SUSTENTABILIDADE E INTELIGÊNCIA REVERSA NA ÓTICA DA LEGISLAÇÃO AMBIENTAL
}

Maira Nunes Farias Portugal Silva ${ }^{1}$

Reginaldo Brito da Costa ${ }^{2}$

Michel Angelo Constantino de Oliveira ${ }^{2}$

Arlinda Cantero Dorsa ${ }^{3}$

Maria Corette Pasa ${ }^{4}$

\section{INTRODUÇÃO}

A logística pode ser entendida como uma das mais antigas atividades humanas, pois a partir da década de 1980, o tema "logística reversa" passa a ser mais explorado tendo em vista o sistema de comunicação, a digitalização das informações e a globalização (LEITE, 2009).

A tendência ao descarte tem aumentado em nossos dias, e como resultado, há uma grande quantidade de produtos que retornam de alguma forma ao ciclo produtivo ou de negócios, seja um produto obsoleto, ou com defeitos ou dentro da garantia, com validade vencida, com excesso de estoque, não consumido ou com pouco uso, retornam ao ciclo de negócios na busca pela recuperação de valor alguma natureza. As empresas têm reconhecido, que além de buscar pelo lucro em suas transações, é necessário um planejamento empresarial, haja vista que se tornou impossível ignorar os reflexos que o retorno dessas quantidades crescentes de produtos de pós-venda e de pós-consumo causam nas operações empresariais.

Segundo Campos (2006), as razões mais frequentes de retorno pós-venda são a inconformidade, o defeito, o não atendimento das expectativas dos clientes. As razões de pós-consumo se manifestam

1 Profa.MsC.Universidade Católica Dom Bosco/UCDB. Campo Grande.MS. maira portugal@hotmail.com

2 Profo. Dr. PPG em Desenvolvimento Local. UCDB. Campo Grande. MS

3 Profa. Dra. PPG em Desenvolvimento Local. UCDB. Campo Grande. MS

4 Profa. Dra. PPGCFA/UFMT. Cuiabá. MT. 
pela obsolência, final de vida útil e destinação final adequada do produto. E sob o aspecto das crescentes quantidades de produtos pós-consumo, ao esgotar os sistemas tradicionais de disposição final, se não equacionadas de forma correta, provocam poluição por contaminação ou por excesso (LEITE, 2009).

Nesse sentido, a importância de destacar as legislações ambientais, como exemplo a Lei de Política Nacional do Meio Ambiente (PNMA), que prevê a responsabilização civil, penal e administrativa, nos casos de infrações cometidas no Meio Ambiente.

\section{O ESTADO DA ARTE PELO VIÉS BIBLIOGRÁFICO}

A Logística Reversa é o retorno de um bem, resíduo ou parte de um produto, sendo proveniente da venda ou do processo de transformação das empresas, que engloba as diferentes formas e possibilidades de retorno do produto após o contato com o cliente final, do consumidor ao varejista ou de um intermediário, que esteja na cadeia produtiva até o fornecedor primário da cadeia. Desta forma, existe duas grandes categorias de canais de distribuição reversos, as de pós-venda e as de pós-consumo (Figura 1).
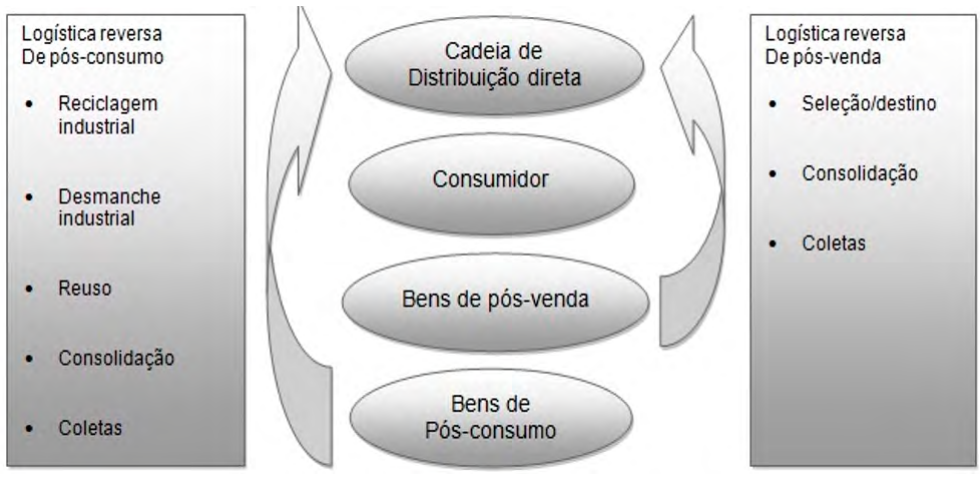

Figura 1. Logística Reversa - área de atuação e etapas reversas Fonte: LEITE (2009).

Para Leite (2009), a primeira área de atuação da Logística que se ocupa em equacionar e operacionalizar o fluxo físico e as informações que estão ligadas aos bens de pós-venda. Esses bens podem voltar sem uso ou com pouco uso, que por diferentes motivos retornam aos diferentes elos da cadeia de distribuição 
direta, que se constituem de uma parte dos canais reversos pelo qual fluem estes produtos.

Sendo que a finalidade desse canal reverso é agregar valor a um produto logístico que é devolvido por razões comerciais, erros no processamento dos pedidos, defeitos ou falhas de funcionamento no produto, avarias no transporte, entre outros motivos. Este fluxo de retorno se estabelecerá entre os diversos elos da cadeia de distribuição direta dependendo do objetivo estratégico ou motivo de seu retorno.

A segunda é a área de atuação da logística reversa que igualmente equaciona e operacionaliza o fluxo físico e as informações correspondentes de bens de pós-consumo descartados pela sociedade, que retornam ao ciclo de negócios ou ao ciclo produtivo pelos canais de distribuição reversos específicos. Constituem-se bens de pós-consumo os produtos em fim de vida útil ou usado com possibilidade de utilização e resíduos industriais em geral. São bens industriais descartados pela sociedade, que tem ciclos de vida de dias ou até mesmo anos, que após o uso pelo primeiro consumidor, tornam-se produtos de pós-consumo e, se apresentarem condições de utilização, podem destinar-se ao mercado de segunda mão (reuso), sendo comercializado diversas vezes até o fim de sua vida útil. Portanto, a forma de reverter corretamente o pós-venda passa pelas etapas de planejar, operar e controlar o fluxo de retorno dos produtos de pós-venda por motivos agrupados nas classificações de Garantia/Qualidade, Comerciais e de Substituições de Componentes.

A categoria classificada como devoluções por Garantia/ Qualidade é aquela nas quais os produtos apresentam defeitos de fabricação ou de funcionamento, avarias no produto ou na embalagem. Estes produtos poderão ser submetidos a consertos ou reformas que permitam retornar ao mercado primário, ou a mercados diferenciados denominado de secundários, agregando-lhes valor comercial novamente. A flexibilidade de retorno é um dos principais aspectos da Logística Reversa de pós-venda, e isso ocorre por meio de contratos estabelecidos ou iniciativas próprias para atender as necessidades apresentadas pelos clientes, agregando valor de diferentes naturezas.

Lacerda (2002) preceitua que os fatores críticos para a eficiência de um processo de Logística Reversa são bons controles de 
entrada, como identificar o estado dos produtos retornados, para facilitar o fluxo ou impedir a entrada de produtos que não atendam as características necessárias para entrarem no processo, e verificar um sistema de informação, no qual seja capaz de rastrear os retornos, monitorar o tempo de ciclo, apresentar o desempenho dos fornecedores com relação às avarias dos produtos.

\section{Aspectos legais e normativos}

As legislações, além do caráter orientador, regulador e disciplinar, possuem componentes de pesadas punições pelo descumprimento das normas, visto que a responsabilidade da coleta e a disposição dos resíduos constituía-se responsabilidade exclusiva do poder público, todavia, essa tendência tem sido modificada com o desenvolvimento da sociedade e dos sistemas de produção. Nesse sentido existe uma série de outras questões de ordem produtiva, tecnológica, como exemplo a Extensão de Responsabilidade de Produto (EPR - extend product responsability) pode ser verificada no sentido de que toda a cadeia industrial é responsável em reduzir os impactos diretos e indiretos de seus processos, produtos e embalagens no meio ambiente, (LEITE, 2009).

Nesta argumentação advém a questão da participação Estatal, pois sobre as práticas de mercado ou até mesmo o equilíbrio deste, visto que o poder público torna-se peça chave na definição de normas, regulamentos, restrições e controle.

\section{Legislações Ambientais}

O tratamento jurídico sobre a questão ambiental tem por objetivo amenizar o impacto, assim regulamentando e responsabilizando pessoas físicas ou jurídicas caso não cumpre com a determinação legal.

Nesse sentido, Tadeu et al (2016, p.20) enfatiza a importância do ambiente legal seguindo alguns critérios como:

a. Legislação relativa à coleta e disposição final:

- Legislação sobre a proibição de lixões e aterros sanitários;

- Legislação sobre a implantação de coleta seletiva; 
- Legislação sobre PTB (product take back), ou seja, responsabilidade do fabricante sobre o canal reverso de seus produtos/embalagens

- Legislação sobre índices mínimos de reciclagem;

- Legislação sobre o valor monetário pago/depositado na aquisição de certos produtos/embalagens.

b. Legislação relativas ao marketing:

- Legislação de incentivos fiscais e creditícios ao conteúdo de reciclados nos produtos;

- Legislação sobre proibição de venda ou uso de certo produtos;

- Legislação sobre a proibição de embalagens descartáveis;

- Legislação sobre rótulos ambientais;

c. Legislação relativas à redução na fonte:

- Legislação de incentivos fiscais e financeiros;

- Legislação de apoio à pesquisa e desenvolvimento de tecnologia e produtos.

No Brasil há as principais legislações visando reciclagem e a diminuição dos impactos gerados pelo lixo, tendo em vista a Política sobre resíduos sólidos; a coleta seletiva domiciliar obrigatória nos Municípios com mais de 150 (cento e cinquenta) mil habitantes; a obrigatoriedade por parte dos fabricantes e distribuidores de produtos agro-veterinários e pneumáticos pela coleta de embalagens e produtos de pós-consumo, e a legislação que traz uma tributação diferenciada as atividades de reciclagem de materiais.

Em 1998 teve início a legislação brasileira que trata do Programa Brasileiro de Reciclagem, com busca constante por alternativas que possam melhor, reduzir e reciclar, tem sido válidas, afim de possuirmos um meio ambiente ecologicamente equilibrado e saudável, haja vista que o melhor método para a destinação dos resíduos é aquela em que o meio ambiente e ganho financeiro sejam combinados de forma que tanto as diretrizes do meio ambiente quanto o lucro sejam aceitáveis, concretizando essa visão de reciclagem (SOUZA; FONSECA, 2008).

Dessa maneira, cabe mencionar que a Agenda 21 propõe que a "sociedade precisa desenvolver formas eficazes de lidar com o 
problema de eliminação cada vez maior de resíduos. Os Governos, juntamente com as indústrias, as famílias e o público em geral, devem envidar um esforço para reduzir a geração de resíduos e de produtos descartados".

\section{A Política Nacional de Resíduos Sólidos}

Em 2 de agosto de 2010 foi instituída a Lei de Política Nacional de Resíduos Sólidos, que foi regulamentada pelo Decreto Lei $n$ ㅇ. $7.404 / 2010$, posto que a referida Lei trata de quais os instrumentos que podemos utilizar para diminuir os impactos ambientais, sendo que um deles é a Logística Reversa, e que assim preceitua:

Art. 8․ São instrumentos da Política Nacional de Resíduos Sólidos, entre outros: [...].

III - a coleta seletiva, os sistemas de logística reversa e outras ferramentas relacionadas à implementação da responsabilidade compartilhada pelo ciclo de vida dos produtos; [...]

O gerenciamento dos resíduos sólidos não se submete a um regime jurídico único, sendo que varia de acordo com a localidade onde são gerados e com o seu conteúdo (FIORILLO, 2013). Neste sentido cabe mencionar que no ano de 2010 o Brasil produziu 60,8 milhões de toneladas de resíduos sólidos urbanos (RODRIGUES, 2013). Segundo a Organização das Nações Unidas (ONU) no ano de 2015, o Brasil produziu cerca de 80 (oitenta) mil toneladas de resíduos sólidos por dia, e que são destinados de forma inadequada. Ou seja, a geração de resíduos aumenta em uma proporção infinita, neste sentido insta elencar:

Assim, enquanto os índices de geração de resíduos aumentavam em proporção geométrica no nosso país (em proporção infinitamente superior ao índice de reciclagem e reutilização), adormecia no Congresso Nacional o Projeto de Lei de criação da Política Nacional de Resíduos Sólidos.

Após nada menos que 20 anos de trâmite no Congresso Nacional, enfim em 2 de agosto de 2010, entrou em vigor a Lei $n$. 12.035, que instituiu a Política Nacional de Resíduos Sólidos.

Era inconcebível que um tema de tamanha magnitude não tivesse sido ainda regulamentado por lei. 
Explica-se a demora pelo fato de que o Projeto de Lei passou por intensos debates e muitas lutas contra lobbies econômicos. Afinal, a presente lei enfrentou problemas (e venceu alguns deles) de grande interesse econômico, como alteração de matrizes energéticas na produção de bens de consumo, responsabilização dos geradores de resíduos (empresas), educação do consumidor e alteração dos padrões de consumo, entre outros aspectos igualmente importantes.

A lei n. 12.035, regulamentada pelo Decreto n.7.404/2010, representa uma grande vitória da coletividade, apesar do atraso, se considerada a importância do tema (ROGRIGUES, 2013, p. 183).

Cabe lembrar que antes da Lei de Política Nacional de Resíduos Sólidos (PNRS) vigente, os poluidores não eram responsabilizados pelos resíduos gerados por seus processos a partir do momento em que estes deixavam a empresa, embora esses resíduos ainda necessitavam de uma destinação adequada. Desse modo, quem arcava com todos os custos e etapas de coleta, transporte, transbordo, tratamento e destinação final ambientalmente adequada dos resíduos sólidos e disposição final ambientalmente adequada dos rejeitos era a própria sociedade.

Assim a PNRS vem para regulamentar e também para apresentar quais os instrumentos que estão disponíveis para minimizar os impactos ambientais, e o que define como logística reversa, há também a previsão da responsabilidade compartilhada sobre a destinação dos resíduos sólidos, visto que é importante a participação de todos, em conjunto, seja o Estado, empresas e consumidores, assim preceitua o artigo 30 da Lei $n=12.0305 / 2010$ :

Art. 30. É instituída a responsabilidade compartilhada pelo ciclo de vida dos produtos, a ser implementada de forma individualizada e encadeada, abrangendo os fabricantes, importadores, distribuidores e comerciantes, os consumidores e os titulares dos serviços públicos de limpeza urbana e de manejo de resíduos sólidos, consoante as atribuições e procedimentos previstos nesta Seção (BRASIL, 2010).

Parágrafo único. A responsabilidade compartilhada pelo ciclo de vida dos produtos tem por objetivo: 
I - compatibilizar interesses entre os agentes econômicos e sociais e os processos de gestão empresarial e mercadológica com os de gestão ambiental, desenvolvendo estratégias sustentáveis;

II - promover o aproveitamento de resíduos sólidos, direcionando-os para a sua cadeia produtiva ou para outras cadeias produtivas;

III - reduzir a geração de resíduos sólidos, o desperdício de materiais, a poluição e os danos ambientais;

IV - incentivar a utilização de insumos de menor agressividade ao meio ambiente e de maior sustentabilidade;

V - estimular o desenvolvimento de mercado, a produção e o consumo de produtos derivados de materiais reciclados e recicláveis;

VI - propiciar que as atividades produtivas alcancem eficiência e sustentabilidade;

VII - incentivar as boas práticas de responsabilidade socioambiental (BRASIL, 2010).

E ainda sobre a responsabilidade compartilhada, o artigo 25 também dispõe:

Art. 250 poder público, o setor empresarial e a coletividade são responsáveis pela efetividade das ações voltadas para assegurar a observância da Política Nacional de Resíduos Sólidos e das diretrizes e demais determinações estabelecidas nesta Lei e em seu regulamento (BRASIL, 2010).

A responsabilidade compartilhada abrange não somente Estado, consumidores e empresas, mas também os fabricantes, importadores, distribuidores e comerciantes, destaca-se assim que o reaproveitamento de materiais, ou seja, a logística reversa, estimulam cada vez mais iniciativas e esforços de implantação para assegurar uma recuperação sustentável, eficiente e eficaz.

\section{Logística Reversa e Ciclo de Vida do Produto}

A vida de um produto, do ponto de vista logístico, não termina com sua entrega ao cliente. Pois, como define a Lei no 12.305/2010, 
o ciclo de vida do produto é uma "[...] série de etapas que envolvem o desenvolvimento do produto, a obtenção de matérias-primas e insumos, o processo produtivo, o consumo e a disposição final."

Nesse processo, com a participação de todos, ocorre o "ciclo de vida do produto", envolvendo fabricantes, comerciantes, empresários, sociedade, sendo que o ciclo é representado conforme demonstra a Figura 2.

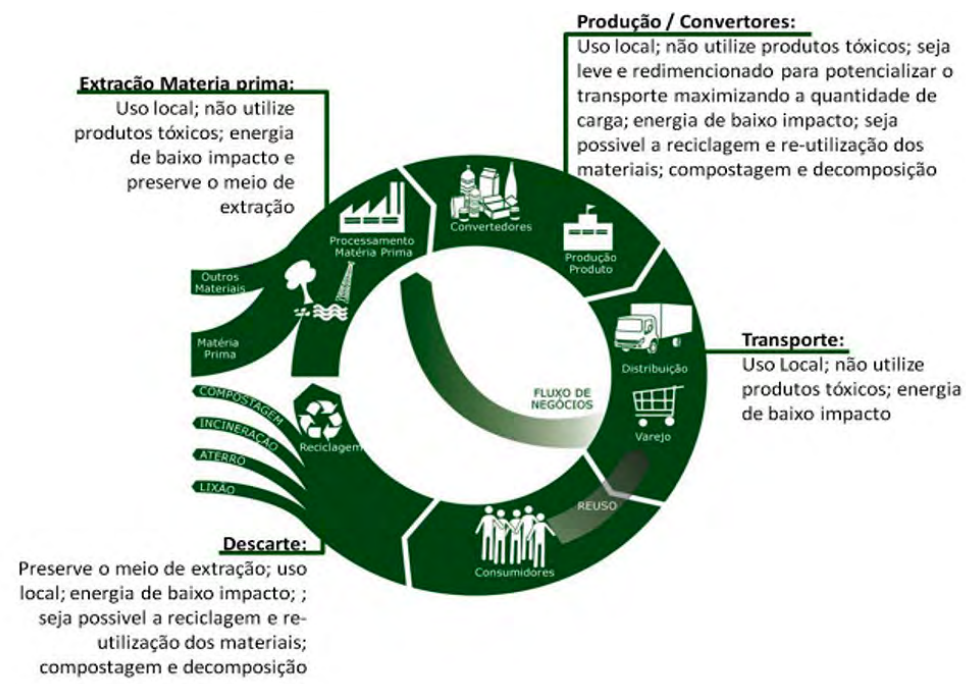

Figura 2. Ciclo de vida do produto

Fonte: BLOGSPOT (2017). Disponível em: <http://migre.me/u3Dzr>. Acesso em 03 out. 2017.

Segundo Leite (2003) a Logística Reversa é a área da logística empresarial que tem como objetivo equacionar os aspectos de logística do retorno dos bens, agregando valor, seja econômico, ambiental e legal, sendo configurada conforme ponderado na Figura 3.

Neste processo, o produto deve retornar a sua origem, não sendo necessário de ser devolvido da mesma forma em que foi fabricado.

Dentro desses movimentos tem-se o fluxo reverso dos produtos de pós-venda e de pós-consumo, agregando assim a ideia da logística reversa, que pode ser definida como a área da logística empresarial que planeja, opera e controla o fluxo reverso de peças a serem reparadas, de embalagens, de produtos vendidos e não 
consumidos, de componentes devolvidos, e de produtos usados para serem reciclados, entre outras possibilidades.

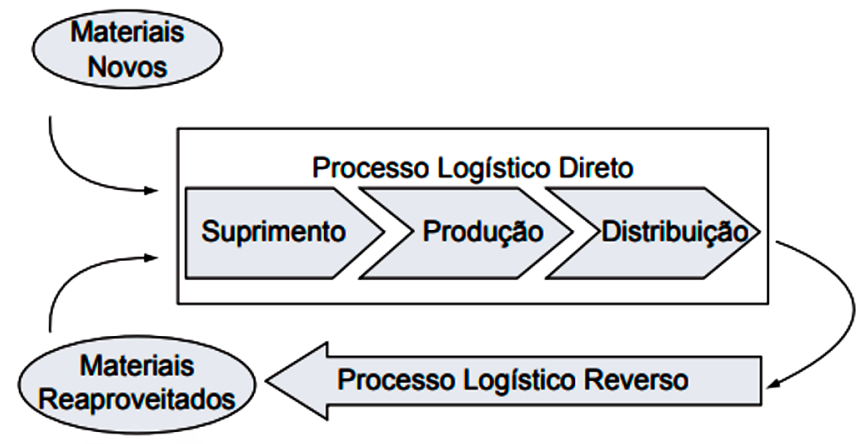

Figura 3. Processo Logístico Reverso

Fonte: LACERDA, 2002, p. 2 apud GONÇALVES; MARINS, 2006, p. 40.

No que se refere aos fluxos reversos, eles podem ser do tipo: ciclo aberto, casos em que os produtos retornados, ao chegar ao final da cadeia reversa, não voltam necessariamente ou diretamente para serem convertidos no mesmo produto, ou ciclo fechado, nesses casos é possível uma maior integração/relação entre o canal direto e o reverso, o material descartado pode retornar na forma de um produto igual ou similar ao original, servindo de insumo direto na cadeia produtiva (LEITE, 2009).

No mesmo sentido, segundo Tadeu et.al (2015, p. 34-35) afirma que os ciclos reversos podem ser abertos e fechados, assim:

Canais de distribuição reversos de ciclo aberto: são CDRs formados pelas diversas etapas de retorno de materiais constituintes dos produtos de pós-consumo: metais, plásticos, vidros, papéis etc., materiais extraídos de diferentes produtos de pós-consumo, visando a reintegração ao ciclo produtivo e substituindo matérias- primas novas na fabricação de diferentes tipos de produtos. Como exemplo, podemos citar: ferro e aços extraídos de automóveis, máquinas e equipamentos, navios, latas de embalagens [...].

Neste aspecto cabe ilustrar o canal de distribuição do ciclo reverso aberto apresentado na Figura 4. 


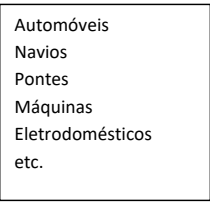

\begin{tabular}{|l|}
\hline Embalagens \\
Tambores \\
Brinquedos \\
Utensílios \\
Computadores \\
etc. \\
\hline
\end{tabular}

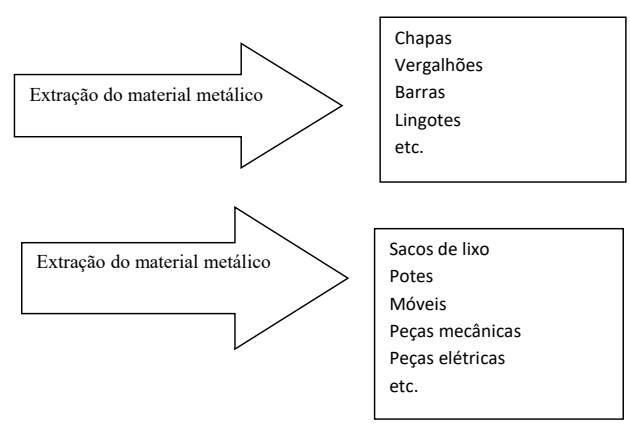

Figura 4. Canal de distribuição do ciclo reverso aberto Fonte: Adaptado de LEITE (2003).

Porém, os canais de distribuições reversas de ciclos fechados têm como característica a utilização dos materiais constituintes de determinado produto descartado ao fim de sua vida útil são extraídos seletivamente dele para a fabricação de um produto similar ao de origem, e neste sentido Tadeu et.al (2015) menciona que por interesses tecnológicos, logísticos e econômicos ou de outra ordem, todas as fases da cadeia produtiva reversa são especializadas para a revalorização do material constituinte de determinado produto. Assim, existem diversos sistemas de distribuição do ciclo reverso fechado, conforme se apresenta na Figura 5.

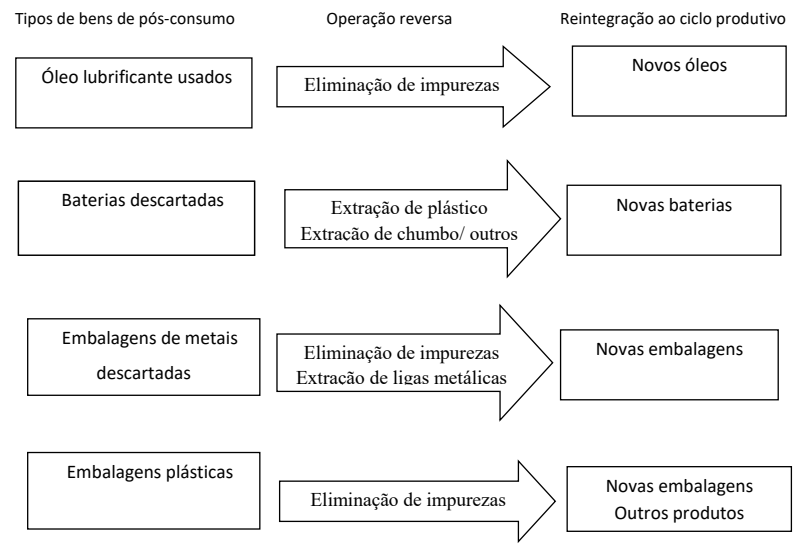

Figura 5. Sistema de distribuição do ciclo reverso fechado

Fonte: Adaptado de LEITE (2003). 
As normas legais relacionadas ao meio ambiente têm pressionado empresas a adotar políticas de Logística Reversa para seus produtos, uma vez que há a necessidade de diferenciação entre serviços oferecidos, sendo que essa realidade se deve à expansão da competitividade empresarial e à crescente necessidade de reduzir custos referentes a matérias primas (FLEISCHMANN et al., 2001).

\section{Resíduos Sólidos e Orgânicos}

Em qualquer parte do mundo as sociedades requerem a transformação de recursos naturais em produtos beneficiados para as suas necessidades em geral. A produção de lixo urbano é de tal intensidade que não é possível conceber uma cidade sem considerar a problemática gerada pelos resíduos sólidos desde a etapa da geração até a disposição final, conforme PEDROSO e SILVA (2000).

A definição dicionarizada do termo resíduo, que significa aquilo que resta de qualquer substância que sofreu alteração de agente exterior. Dessa forma, para dizer que alguns estudiosos sugerem que se use o termo "resíduo" e não "lixo", posto que este último poderia dar a ideia de que se trata de algo que não serviria mais. $\mathrm{E}$ a palavra "resíduo" poderia ser entendida como algo que sobrou, mas que poderia ser usada para outros fins (BRASIL, 1987).

Neste conceito, a Lei no 12.305/2010, baseada na norma técnica da ABNT de 1987, define os resíduos sólidos como:

Material, substância, objeto ou bem descartado resultante de atividades humanas em sociedade, a cuja destinação final se procede, se propõe proceder ou se está obrigado a proceder, nos estados sólido ou semissólido, bem como gases contidos em recipientes e líquidos cujas particularidades tornem inviável o seu lançamento na rede pública de esgotos ou em corpos d'água, ou exijam para isso soluções técnica ou economicamente inviáveis em face da melhor tecnologia disponível (BRASIL, 1987).

\section{Classificação e caracterização dos resíduos sólidos urbanos e orgânicos}

Cada sociedade produz diversos tipos de lixo, ou seja, uma mistura de materiais que variam em função de hábitos e costumes da população, do clima e da estação, e as atividades econômicas, 
e que muda ao longo do tempo. A classificação mais recorrente é trazida pela norma NBR 10004/1987 que classifica os resíduos sólidos quanta a sua periculosidade, ou seja, resíduos em função de suas propriedades físicas, químicas ou infectocontagiosas, que podem representar potencial de risco à saúde pública e ao meio ambiente, conforme demonstrado no Quadro 1.

\begin{tabular}{|c|c|c|}
\hline $\begin{array}{l}\text { TIPOLOGIA DE RESÍ- } \\
\text { DUOS SÓLIDOS }\end{array}$ & & CARACTERÍSTICAS \\
\hline Classe I & Perigosos & $\begin{array}{l}\text { Pelas suas características de inflamabilida- } \\
\text { de, corrosividade, reatividade, toxidade e } \\
\text { patogenicidade, podem apresentar riscos à } \\
\text { saúde pública,contribuindo para o aumento } \\
\text { da mortalidade ou efeitos adversos ao meio } \\
\text { ambiente manuseados forma inadequada. }\end{array}$ \\
\hline \multirow[t]{2}{*}{ Classe II } & $\begin{array}{l}\text { Não Perigoso } \\
\text { Classe II A - Não } \\
\text { Inertes }\end{array}$ & $\begin{array}{l}\text { Incluem-se nesta classe os resíduos potencial- } \\
\text { mente biodegradáveis ou combustíveis. }\end{array}$ \\
\hline & $\begin{array}{l}\text { Classe II B - } \\
\text { Inertes }\end{array}$ & $\begin{array}{l}\text { Perfazem esta classe os resíduos considera- } \\
\text { dos inertes e não combustíveis. }\end{array}$ \\
\hline
\end{tabular}

Quadro 1. Classificação dos resíduos sólidos quanto à periculosidade Fonte: NBR 10004/2004.

Nesse mesmo sentido, cabe esclarecer que na Lei $\mathrm{n}$ 12.305/2010, de forma parecida, no seu artigo 13으 faz esta classificação quanto à origem e quanto à periculosidade, o que pode ser visto no Quadro 2.

\begin{tabular}{|c|c|c|}
\hline \multicolumn{2}{|r|}{ TIPOLOGIA DE RESÍDUOS SÓLIDOS } & \multirow{2}{*}{$\begin{array}{l}\text { ORIGEM } \\
\begin{array}{l}\text { Os originários de atividades domésticas em } \\
\text { residências urbanas }\end{array}\end{array}$} \\
\hline A) & Resíduos domiciliares & \\
\hline B) & Resíduos de limpeza urbana & $\begin{array}{l}\text { Os originários da varrição, limpeza de logra- } \\
\text { douros e vias públicas e outros serviços de } \\
\text { limpeza urbana }\end{array}$ \\
\hline C) & Resíduos sólidos urbanos & Os englobados nas alíneas "a" e "b". \\
\hline D) & $\begin{array}{l}\text { Resíduos de estabelecimentos } \\
\text { comerciais e prestadores de } \\
\text { serviços }\end{array}$ & $\begin{array}{l}\text { Os gerados nessas atividades, excetuados os } \\
\text { referidos nas alíneas "b", "e", "g", " } h \text { " e "j" }\end{array}$ \\
\hline E) & $\begin{array}{l}\text { Resíduos dos serviços públicos de } \\
\text { saneamento básico }\end{array}$ & $\begin{array}{c}\text { Os gerados nessas atividades, excetuados os } \\
\text { referidos na alínea "c" }\end{array}$ \\
\hline F) & Resíduos industriais & $\begin{array}{l}\text { Os gerados nos processos produtivos e insta- } \\
\text { lações industriais. }\end{array}$ \\
\hline
\end{tabular}




\begin{tabular}{c|l|c}
\hline G) & Resíduos de serviços de saúde & $\begin{array}{c}\text { Os gerados nos serviços de saúde, conforme } \\
\text { definido em regulamento ou em normas esta- } \\
\text { belecidas pelos órgãos do Sisnama e do SNVS }\end{array}$ \\
\hline H) & Resíduos da construção civil & $\begin{array}{c}\text { Os gerados nas construções, reformas, re- } \\
\text { paros e demolições de obras de construção } \\
\text { civil, incluídos os resultantes da preparação e } \\
\text { escavação de terrenos para obras civis. }\end{array}$ \\
\hline I) & Resíduos agrossilvopastoris & $\begin{array}{r}\text { Os gerados nas atividades agropecuárias } \\
\text { e silviculturais, incluídos os relacionados a } \\
\text { insumos utilizados nessas atividades. }\end{array}$ \\
\hline J) & Resíduos de serviços de & $\begin{array}{c}\text { Os originários de portos, aeroportos, termi- } \\
\text { nais alfandegários, rodoviários e ferroviários e } \\
\text { passagens de fronteira. }\end{array}$ \\
\hline K) & Resíduos de mineração & $\begin{array}{r}\text { Os gerados na atividade de pesquisa, extra- } \\
\text { ção ou beneficiamento de minérios. }\end{array}$ \\
\hline
\end{tabular}

Quadro 2. Classificação dos resíduos sólidos quanto à origem

Fonte: Adaptado da Lei no 12.305/2010.

Em relação à classificação quanto à periculosidade, segundo a Lei $n$ o 12.305/2010, faz a diferença entre resíduos perigosos e não perigosos:

Resíduos perigosos: aqueles que, em razão de suas características de inflamabilidade, corrosividade, reatividade, toxicidade, patogenicidade, carcinogenicidade, teratogenicidade e mutagenicidade, apresentam significativo risco à saúde pública ou à qualidade ambiental, de acordo com lei, regulamento ou norma técnica; b) Resíduos não perigosos: aqueles não enquadrados na alínea 'a' (BRASIL, 2010).

O Quadro 3, traz a caracterização dos resíduos sólidos urbanos, que segundo Zanta e Ferreira (2003) é da composição gravimétrica dos resíduos se distingue os tipos de lixos existentes numa amostra, pois poderá ocorrer várias categorias possíveis de resíduos.

\begin{tabular}{l|c}
\hline \multicolumn{1}{c|}{ CATEGORIA } & EXEMPLOS \\
\hline Orgânico putrescível & Restos alimentares, flores, podas de árvores. \\
\hline Plástico & $\begin{array}{c}\text { Sacos, sacolas, embalagens de refrigerantes, água e leite, } \\
\text { recipientes de produtos de limpeza, beleza e alimentícios, } \\
\text { esponjas, isopor, utensílios de cozinha, látex, sacos de } \\
\text { ráfia, potes, filmes, frascos, garrafas, etc. }\end{array}$ \\
\hline Papel e papelão & $\begin{array}{c}\text { Caixas, revistas, jornais, cartões, papel, pratos, cadernos, } \\
\text { livros, pastas, fotocópias, rascunhos, envelopes, cartões. }\end{array}$ \\
\hline
\end{tabular}




\begin{tabular}{l|c}
\hline Vidro & $\begin{array}{c}\text { Copos, garrafas de bebidas, pratos, espelhos, embalagens } \\
\text { de produtos de limpeza, beleza e alimentícios. }\end{array}$ \\
\hline Metal ferroso & Palha de aço, alfinetes, agulhas, embalagens de alimen- \\
tos.
\end{tabular}

Quadro 3. Exemplos básicos de cada categoria de Resíduos Sólidos Urbanos Fonte: Adaptado de Pessin, et al. (2002).

\section{CONSIDERAÇÕES FINAIS}

No atual cenário do país em que a temática sustentabilidade está em evidência e o lixo passou a ser um problema global, a utilização de resíduos orgânicos para a produção de adubo é uma alternativa sustentável e desejável, tendo em vista o acúmulo desse produto na natureza. O seu aproveitamento surge como uma alternativa empresarial associada ao desenvolvimento econômico mundial, através da logística reversa que agrega valor às diversas cadeias produtivas sob às condições legislativas vigentes que protegem o meio ambiente.

A utilização dos resíduos orgânicos que sobram ou que não foram consumidos por estar fora do prazo de validade é uma forma aplicativa de inteligência reversa ou logística reversa, que se destaca 
positivamente na redução de lixo, especialmente orgânico, amenizando os impactos ambientais, uma vez que grande parte desse resíduo "in natura" tem a sua destinação final o meio ambiente, causando sérios problemas à saúde humana.

\section{REFERÊNCIAS}

ABRAMOVAY, Ricardo. A Formação do Capital Social para o Desenvolvimento Sustentável. In: II FÓRUM CONTAG DE COOPERAÇÃO TÉCNICA. Anais. São Luiz-MA, 1998.

ALMEIDA. R.G. Sistemas Agrossilvipastoris: benefícios técnicos, econômicos, ambientais e sociais. In: VII ENCONTRO SOBRE ZOOTECNIA DE MATO GROSSO DO SUL, 7, 2010, Campo Grande - MS. Anais...Campo Grande: UFMS, 2011. p. 1-10. 1 CD-ROM.

ASSOCIAÇÃO BRASILEIRA DE NORMAS TÉCNICAS. NBR 10004/2004 - Resíduos sólidos: classificação. Mai. 2004.

NBR 13463/1995 - Coleta de resíduos sólidos: classificação. Set. 1995.

NBR-8418 - Apresentação de projetos de aterros de resíduos industriais perigosos. Dez. 1983.

. NBR 13463/1995 - Coleta de resíduos sólidos: classificação. Dez. 1995.

ÁVILA, V.F. de. Cultura de Subdesenvolvimento e Desenvolvimento Local. Sobral, Edições UVA, 2006.

BANKER, R.; CHARNES, A.; COOPER, W. W. Some Models for Estimating Technical and Scale Ineficiences in Data Envelopment Analysis. Management Science, v. 30, p.1078-1092, 1984.

BARQUERO. L. V. Desarrolo Económico Local y Descentralización: Aproximación a Um Marco Conceptual. Cepal/ GTZ. 2000.

BALLOU, R.H. Logística Empresarial. São Paulo: Atlas, 2001.

CHARNES, A.; COOPER, W.W.; RHODES, E. Measuring the efficiency of decision making units. European Journal of Operational Research, v. 2, p. 429-444, 1978.

DORNIER, P.; ERNEST, R.; FENDER, M.; KOUVELIS, P. Logística e Operações Globais. São Paulo: Atlas, 2000.

. Logística Empresarial: Transporte, administração de materiais e distribuição física. São Paulo, Atlas, 2007.

BRASIL. Lei no 3.234, de 3 de dezembro de 2003 - Institui a Política de Gestão de Reciclagem de Resíduos Sólidos da Construção Civil e dá outras providências. Disponível em <http://www.tc.df.gov.br/SINJ/Arquivo.ashx?id norma consolidado=51182 >. Acesso em 06 mar. 2016. 
Lei no 3.234, de 3 de dezembro de 2003. Institui a Política de Gestão de Reciclagem de Resíduos Sólidos da Construção Civil e dá outras providências. Disponível em <http://www.tc.df.gov.br/SINJ/Arquivo.ashx?id norma consolidado=51182 $>$. Acesso em 06 mar. 2016.

. Lei no 12.305, de 2 de agosto de 2010. Institui a Política Nacional de Resíduos Sólidos, cria o Comitê Interministerial da Política Nacional de Resíduos Sólidos e o Comitê Orientador para a Implantação dos Sistemas de Logística Reversa, e dá outras providências. Disponível em <https://www.planalto.gov.br/ ccivil 03/ ato2007-2010/2010/decreto/d7404.htm>. Acesso em: 05 mar. 2016.

BARBIERI, J. C.; DIAS, M. Logística Reversa como Instrumento de Programas de Produção e Consumo Sustentáveis. Tecnologística. São Paulo, n. 77, p. 58-69, 2002.

BENKO, G. Novo Debate Regional: Posições em Confronto. In: BENKO, Georges; LIPIETZ, Alain (Orgs.). As Regiões Ganhadoras: Os Novos Paradigmas da Geografia Econômica. Portugal: CELTA LDA, 1998.

BOWERSOX, D. J.; CLOSS, D. J. Logistics Management: the integrate supply chain process. McGraw-Hill, 1996.

CAMARGO, A.L.B. As Dimensões e os Desafios do Desenvolvimento Sustentável: concepções, entraves e implicações a sociedade humana. 2002. 198 f. Dissertação (Mestrado em Engenharia de Produção) - UFSC, Florianópolis-SC.

CHING. Y. H. Gestão de Estoques na Cadeia de Logística Integrada - supply chain. 3. ed. São Paulo: Atlas, 2006.

CHRISTOPHER, M. Logística e Gerenciamento da Cadeia de Suprimentos. São Paulo: Pioneira, 1999.

Logística e Gerenciamento da Cadeia de Suprimentos. Trad. Mauro de Campos Silva. 2. ed. São Paulo: Thomson Learning, 2007.

CLM (Council of Logistics Management). Reuse and Recycling Reverse Logistics Opportunities. Illinois: Council of Logistics Management, 1993.

COPACINO, William C. Suplly Chain Management: The Basics and Beyond (Resource Management). Flórida: CRC Press 1997.

CORRÊA, H. L. Gestão de Redes de Suprimento: integrando cadeias de suprimento no mundo globalizado. São Paulo: Atlas, 2010.

DOWBOR, Ladislau. Desenvolvimento Local e Apropriação dos Processos Econômicos. Revista do Instituto de Estudos Brasileiros, v.51, 2010.

ELIZALDE, A. Desarrollo a Escala Humana: conceptos y experiências. Interações - Revista Internacional de Desenvolvimento Local, Campo Grande, MS, v.1, n. 1, p. 51-62, set. 2000.

FIORILLO. C.A.P. Curso de Direito Ambiental Brasileiro. 14ae ed. Saraiva. 2013.

FURTADO, C. Introdução ao desenvolvimento: enfoque histórico estrutural. Rio de Janeiro: Paz e Terra, 2000. 
GONÇALVES, M.E.; MARINS, F.A.S. Logística Reversa numa empresa de laminação de vidros: um estudo de caso. Gestão \& Produção, v.13, n.3, p.397-410, set-dez, 2004.

IPCC - Intergovernmental Panel on Climate Change. Climate Change 2007: Synthesis Report. Disponível em: <http://www.ipcc.ch/publications and data/publications ipcc fourth assessment report synthesis report.htm>. Acesso em: 19 jun. 2016.

JACOBI, P. R.; BESEN, G. R. Gestão de resíduos sólidos em São Paulo: desafios da sustentabilidade. Estudos Avançados.Vol.25, no.71, São Paulo Jan./Abr. 2011.

LACERDA, L. Logística Reversa: uma visão sobre os conceitos básicos e as práticas operacionais. In: CONGRESSO NACIONAL DE ENGENHARIA DE PRODUÇÃO, 2000, Rio de Janeiro. Anais... Rio de Janeiro: EE/UFRJ, 2000.

LASTRES, H.M.M. (Org.). Globalização e Inovação Localizada: Experiências de Sistemas Locais do Mercosul. Brasília: IBICT/MCT, 1999, p. 31-71.

LEITE, José Rubens Morato. Sociedade de Risco e Estado. In. CANOTILHO, José Joaquim Gomes. Direito Constitucional Ambiental Brasileiro. São Paulo: Saraiva, 2007.

LEITE, P. R. Logística Reversa: a complexidade do retorno de produtos. Revista Tecnologística, São Paulo, dez. 2009.

. Logística Reversa e a política nacional de resíduos sólidos. Revista Tecnologística, São Paulo, nov.2010.

. Logística Reversa: meio ambiente e competividade. São Paulo: Prentice Hall, 2003.

LOZADA, H. R.; MINTU-WIMSATT, A.T. Green-based Innovatin: sustainnable development in product management. In: POLONSKY, J. et al. Environmental Marketing: strategies practice, theory and research. Nova York: Hawort Press, 1995.

MATTAR, F.N. Pesquisa de Marketing. São Paulo: Atlas, 1993. (Vol. 1).

MCGRANAHAN, G.; SATTERTHWAITE, D. The environmental dimensions of sustainable development for cities. Geography, v.87, n.3, p.213-226, 2002.

MARQUES, Heitor Romero et al. Metodologia da Pesquisa e do Trabalho Cientifico. 5. ed. rev. e atual. Campo Grande - MS: UCDB, 2017.

MARTINS, M.; SILVA, G. Logística Reversa no Brasil: estado das práticas. In: XXVI ENCONTRO NACIONAL DE ENGENHARIA DE PRODUÇÃO, 10, 2006, Fortaleza-CE. Anais... Fortaleza-CE, 2006, p. 1-7.

MMA. Gestão de Resíduos Orgânicos, Disponível em http://www.mma.gov.br/ cidades-sustentaveis/residuos-solidos/gest $\% \mathrm{C} 3 \% \mathrm{~A} 30$-de-res $\% \mathrm{C} 3 \% \mathrm{ADduos}$-org\%C3\%A2nicos. Acesso em: 15 out. 2017.

MULLER, C.F. Logística Reversa Meio Ambiente e Produtividade. Disponível em <http://web-resol.org/textos/artigo01 1.pdf>. Acesso em: 18 jul. 2017. 
NOVAES, A. G. Logística e Gerenciamento da Cadeia de Distribuição. Rio de Janeiro: Elsevier, 2007.

ONU - Organização das Nações Unidas. Agenda 21. Disponível em: < $\underline{\text { http://www. }}$ onu.org.br/rio20/img/2012/01/agenda21.pdf>. Acesso em: 04 out. 2017.

ONU-BR - Nações Unidas no Brasil. No Brasil, 80 mil toneladas de resíduos sólidos são descartadas de forma inadequada por dia, afirma ONU. Disponível em <https://nacoesunidas.org/no-brasil-80-mil-toneladas-de-residuos-solidos-sao-descartados-de-forma-inadequada-afirma-onu/ >. Acesso em 19 set. 2017.

PEDROZO, E.A.; SILVA, Tania Nunes da. O Desenvolvimento Sustentável e a Teoria Sistêmica. Revista Eletrônica de Administração, Porto Alegre, v.18, n.6, p.1-30, 2000.

OBLADEN. N. L. et al. Guia para Elaboração de Projetos de Aterros Sanitários para Resíduos Sólidos Urbanos. Curitiba: CREA-PR, 2009.

OLIVEIRA, M.A.C.; SAMBUICHI, R. H. R.; SILVA, A.P.M. Experiências Agroecológicas Brasileiras: uma Análise à Luz do Desenvolvimento Local. Revista Brasileira de Agroecologia, v. 8, p. 1/2 -15,2013.

PESSIN, N.; DE CONTO, S. M.; QUISSINI, C. S. Componentes Potencialmente Perigosos nos Resíduos Sólidos Domésticos - estudo de caso de sete municípios de pequeno porte da região do Vale do Caí/RS. In: SEMINÁRIO NACIONAL DE RESÍDUOS SÓLIDOS, 6, 2002, Gramado. Anais...Gramado: ABES, 2002, CD-ROM.

RODRIGUES, Marcelo A. Direito Ambiental Esquematizado. São Paulo: Saraiva, 2013.

ROGERS, D. S; TIBBEN-LEMBKE, R.S. Going Backwards: reverse logistics trends and practices. Reno: Universidade de Nevada, 1999.

SEGURANÇA DO TRABALHO ACZ. NBR 1004: Classificação dos Resíduos Sólidos. Disponível em: <http://www.segurancadotrabalhoacz.com.br/nbr-10004-clasificacao-dos-residuos-solidos/>. Acesso em: 01 ago. 2017.

SETAC. Society of Environmental Toxicology and Chemistry. Guidelines for Life-Cycle Assessment: A 'Code of Practice', SETAC, Brussels, 1993.

SIRVINSKAS, L. P. Manual de Direito Ambiental. 10. ed. São Paulo: Saraiva, 2013.

SOUZA, S. F.; FONSECA, S. U. L. Logística reversa: oportunidades para redução de custos em decorrência da evolução do fator ecológico. In: SEMINÁRIO EM ADMINISTRAÇÃO,11, 2008, São Paulo. Anais... São Paulo: FEA USP, 2008. Disponívelem<http://www.ead.fea.usp.br/Semead/11semead/resultado/an resumo. asp?cod trabalho=87> Acesso em: 06 abr. 2016.

TADEU, H.F.B. et al. Logística Reversa e Sustentabilidade. 1. ed. São Paulo: Saraiva, 2015.

TRIGUEIRO, F. G. R. Logística Reversa: a gestão do ciclo de vida do produto. 2003.Disponível em: <http://www.guialog.com.br/artigos-log.htm>. Acesso em: 06 abr. 2016. 
THOMÉ, R. Manual de Direito Ambiental. 3. ed. Salvador: Jus PODIVUM, 2013.

URBAN WORLD FORUM. Reports On Dialogues - Sustainable Urbanization. Disponível em: <http://www.unchs.org/uf/aii.html>. Acesso em: 19 jun. 2016.

YIN, R.K. Estudo de caso: planejamento e métodos. 3. ed. Porto Alegre: Bookman, 2005.

ZANTA, Viviana Maria; FERREIA, Cynthia Fantoni Alves. Gerenciamento Integrado De Resíduos Sólidos Urbanos. In: CASTILHOS JÚNIOR, Armando Borges de. (Coord.). Resíduos Sólidos Urbanos: aterro sustentável para município de pequeno porte. Rio de Janeiro: ABES, 2003.

ZIMERMANN, R. A.; GRAEML, A. R. Logística reversa: conceitos e componentes do sistema. Estudo de caso: Teletex Computadores e Sistemas. In: XXII Encontro Nacional de Engenharia de Produção, 10, 2003, Ouro Preto. Anais... Ouro Preto-MG, 2003.

YIN, Robert K. Estudo de Caso: planejamento e métodos. 2 ed. Porto Alegre: Bookman, 2001. 